\title{
THE PUSHOUT STRENGTH OF CONCRETE PAVEMENT SLAB AND CLAY SOIL LAYERS
}

\author{
${ }^{*}$ Sattam D. Ghanim ${ }^{1}$
}

\author{
Qais s. Banyhussan ${ }^{1}$
}

\author{
Thulfiqar A. Aboaljus ${ }^{1}$
}

1) Highway and Transportation Engineering Department, College of Engineering, Mustansiriyah University, Baghdad, Iraq

\begin{abstract}
The frictional forces between the concrete slab and base has been combined with the movements of the horizontal slab that have been induced by variations of the moisture and temperature in concrete slabs. The frictional drag that acts on the slab bottom as a result of base friction is in an opposite horizontal slab displacement direction, and resist movements of the horizontal slab. A condition of smoother interface provides lower resistance to slab movement. On the other hand, rough interfaces are beneficial in the reduction of the load-related stresses. As bonding degree between slab and foundation affects the friction that has been mobilized at interface, a realistic evaluation of friction of the interface is required for the rational designs of the concrete pavement. In this work, push-off test has been performed. Based upon results of the friction tests, the friction characteristics of concrete and soil have been researched. The parameters that influence the maximal displacement and friction coefficient are (interface state, rate of movement) for friction and (rate of movement, interface condition) for the displacements, respectively. Finally, once the applied force reaches a stable state, the frictional force increases dramatically. The most important influence on this force is the interface state, which is accompanied by movement rate. The change of the interface from a smooth to a rough surface increases the overall coefficient of friction.
\end{abstract}

Keywords: clay soil; push-off test; displacement; friction; slab.

\section{Introduction}

Concrete pavements present a larger challenge to the designer compared to the columns and beams. Not only must vehicle load values be calculated, but environmental load values have to be calculated as well. Those environmental stresses can induce cracking not only throughout pavement's service life, but throughout building phase as well, while concrete hardens. As a result, the designer must consider the qualities of the concrete, beginning with installation, as well as the amount of the environmental stressors to which the pavement is subjected. The frictional forces between concrete slab and base is accompanied by the movements of the horizontal slab, which have been induced by temperature and moisture variations in the concrete slabs.

Frictional forces act in the opposite direction of horizontal slab movements and develops the stress in slab. The rational frictional forces evaluations between the slab and the base have been found important for designing the slab thickness, joint sealing, and reinforced steel in the concrete pavements. The friction-horizontal displacement relationship has been utilized as input for the systems which have been lately developed that can mechanically anticipate stress and movements of slabs, which has been caused by changes in the temperature and the humidity in slab [1], [2]. A reasonable estimate of base

*Corresponding Author: edma014@uomustansiriyah.edu.iq 
friction is necessary for the determination of practical maximal tensile stress, which could be employed in designing the tie bars, slab thickness, and reinforcement steel for concrete pavement. The estimations of the base friction may be one of the major factors as well in the joint seal design due to the fact that the joint sealant extends similarly to joint opening, the two caused by nearby thermal contraction motions and drying shrinkage. Frictional resistance is increased while applied force is increased, and they remain in a state of equilibrium, to the point of reaching maximal laterally applied force value, which has been mentioned in general, as coefficient of static friction that may be obtained through the division of the force by the value of the weight. Whenever exceeding maximal force of the frictional resistance, the block starts moving. The value of the frictional resistance is reduced to the maximal dynamic friction resistance. The factor of the dynamic friction will be less than the factor of the static friction permanently. They may be computed with the use of an equivalent approach [10]. The characteristics of those coefficients appear to be: independently applied force, independent of contacting surface areas, and depending upon the nature of surfaces that are in contact and precise surface conditions [4]. In the case of a concrete plate contract due to the reduction in the temperature, concrete creeping or humidity decline, generated frictional forces. As soon as this happens, the friction of the interface resists movements. The resistance of the movement plays a role in the production of direct tensile stress in concrete. Several researchers have observed the characteristics of the inter-layer friction between sub-base and concrete pavement through performing the pushoff test. The approach that has been carried out in preceding push-off test was fundamentally for the calculation of concrete test slab displacement during applications of horizontal forces that induct the movement. [10] Have studied the direction of the sliding plane, which has been observed at slab-base interface in loose, unbound base cases, like the clay, loam, and granular base.

\section{The Objectives of Present Work}

The key objective of the present study is to estimate the friction coefficient between concrete pavement and clay soil layer. For catching the objective of this work, push-off test was performed with 3 variables, which are (cement stabilization, rate movement, and condition of the interface).

\section{Utilized Materials}

\subsection{Concrete}

The concrete that has a value of the compressive strength of (31MPa in 28days) has been utilized. The mix proportions (in other words, cement, gravel and sand) that were adopted for concrete slabs have been (1:2.20:3.20) based upon characteristics that have been discussed by [3], as listed in table1, achieving a compressive strength of higher than $30 \mathrm{MPa}$. The proportion values of the mixture have been depicted with maximal aggregate size of $19 \mathrm{~mm}$, both fine and coarse aggregate are matching the gradation based on [9].

Table1. Mix Proportion of Concrete Slabs.

\begin{tabular}{cccc}
\hline \multicolumn{4}{c}{ Unit $(\mathrm{kg} / \mathrm{m} 3)$} \\
Water & Cement & Fine & Coarse \\
140 & 350 & 775 & 1135 \\
\hline Slump & \multicolumn{2}{c}{ Water/Cement $(\%)$} & Fine Agg. \\
60 & \multicolumn{2}{c}{40} & 40 \\
\hline
\end{tabular}

\subsection{Clay Soil Base Layer}

Clay soil layer has been utilized then compacted, (200mm) thick, satisfying specification grading based on [9]. 


\subsection{Poly-Ethylene Sheet}

A poly-ethylene nylon layer of a $(125 \mu \mathrm{m})$ thickness has been placed under slabs for the smooth frictions.

\section{Push-Off Testing}

Push-off test has been carried out at Materials Laboratory in the Engineering College / Dept. of Civil Engineering/ Al-Mustansiriya Univ.; field test was conducted in testing box in $(4.1 \mathrm{~m})$ long $(2.1 \mathrm{~m})$ wide. Base layer in the box was laid in the whole area of the box, as can be seen in the 3D testing room diagram that has been illustrated in Fig1. This test was performed by the concrete slabs that were put on top of a variety of the types of the interface, 2 different conditions of the interface were taken under consideration; test slab was cast directly on the soil. A poly-ethylene sheet was located between testing slab and base layer. A variety of the researches utilized pushoff testing in the past years, however, only 1 local research has been carried out by [2]. As it has been depicted in Fig1, 6 concrete slabs of (1000mm x 500mm) size, with a (150mm) thickness have been (concrete slab cast directly on the base layer, as well as a poly-ethylene sheet that has been placed between clay soil and concrete slab. The experimentations have been performed for rough interface (without the polyethylene sheet) and smooth interfaces with the poly-ethylene sheet for the normal as well as the cement stabilized clay soils.

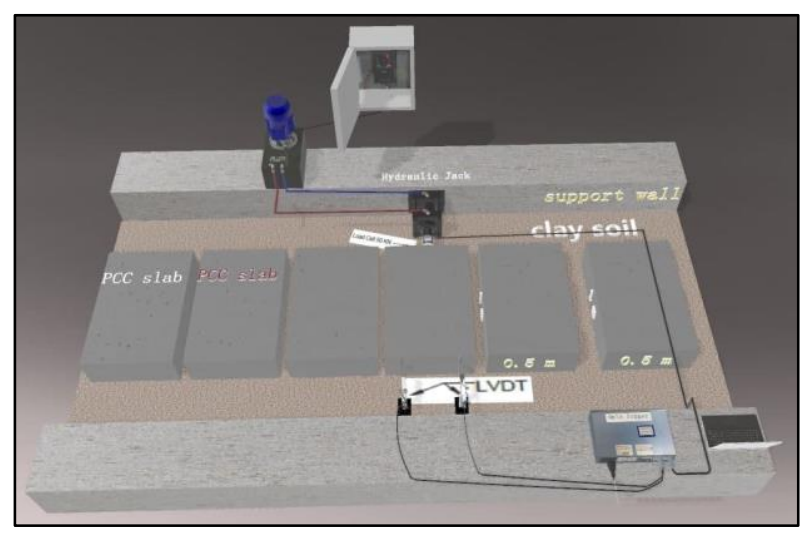

Figure 1. Diagram of the testing room.
The series of the variety of the parameters that were considered in experiential program have been given in table2. Totally 12 slabs were cast. Each 6 slabs denote series have included 3 slabs. A hydraulic jack that has been supported on the support wall of the testing box was deployed for push-off testing. The horizontally applied force was assessed with the use of a $(50 \mathrm{KN})$ capacity load cell, as can be seen from plate1. Slabs that were attached roughly to base layer have been pushed by a $(200 \mathrm{KN})$ capacity hydraulic jack. The horizontal displacement of the slab has been observed with 2 linear variable differential transformers (LVDT) (i.e. electrical converter that has been utilized for the calculation of the linear displacements). Experimental setups of the test slab with hydraulic jack, load cell, (LVDT), computer and data logger have been similar methods utilized earlier by the study that has been performed in [2]. For the slabs with the smooth interfaces, a $(125 \mu \mathrm{m})$ thickness sheet of the poly-ethylene had been laid flat without the creases over the base layer prior to pouring concrete slabs. Push-off test was conducted through the application of horizontal forces on the slabs. For all series, push-off test has been carried out in 3 different rates of movement, which are $(6 \mathrm{~cm} / \mathrm{h}, 9 \mathrm{~cm} / \mathrm{h}$, and $12 \mathrm{~cm} / \mathrm{h})$; the mean displacement value has been recorded by 2 (LVDT), representing the displacement of the slab.

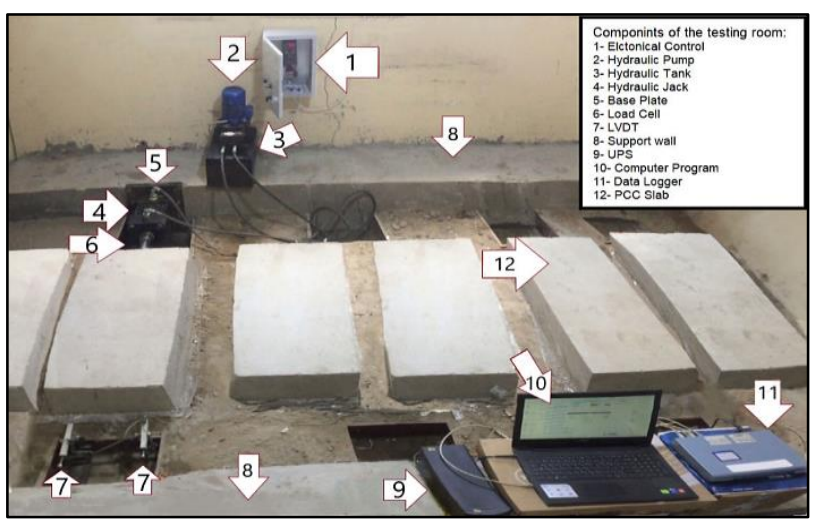

Plate1. Slab test that includes hydraulic jack, load cell, pump, data logger, LVDT and PC, in addition to other components 


\section{Results and Discussion}

\subsection{Displacement Curves vs. Friction Resistance Forces}

For that push-off testing series, numerous cycles have been performed. Only $1^{\text {st }}$ value has been taken, due to the fact that it is representing maximal FRF (i.e. friction resistance force) and includes the most conclusive impact on displacements, which has been in agreement with [2]. Following the performance of all measurements and checks, slabs have been lifted from pit for the purpose of inspecting the bottom surfaces. It has been discovered that surfaces have been quite smooth in the case of the use of polythene layer, which stayed fixed to the bottom of the slab and created some flat plane for slab to be sliding over base. Even following removal of slabs, sub-base showed no signs of the considerable distress. A thin base material coat has been attached to the surface of the bottom of the slab in rough conditions, resisting more than the smooth conditions. Those statements are helpful for the justification of results that have been illustrated in figure2, showing FRF with the relationships of the displacement for the rough interface slab with no stabilization, movement rate $(6 \mathrm{~cm} / \mathrm{hr}$.).

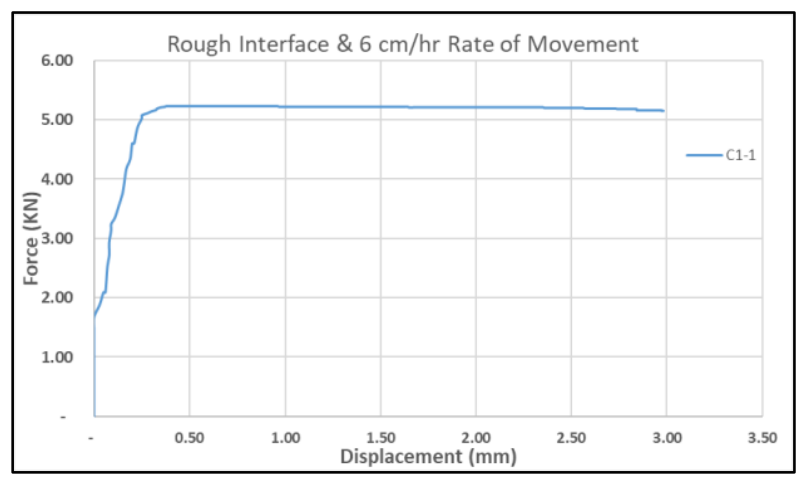

Figure 2. Evaluation of FRF and displacement

From maximal FRF against the relationships of the displacement, push-off test results have been listed in table $2 \&$ table 3 . Results have shown the maximal FRF for 2 interface condition types (in other words, rough and smooth), and 3 movement rates. Initial value of $\mu$ at interface of the slab and the base layer in every cycle had been calculated from (eq1):

$\mu=F / N$

$\mu$ represents the value of the initial friction coefficient.

$F$ represents the force of Friction resistance that has been needed to push the slab, (KN).

$N$ represents the slab weight, $(\mathrm{KN})$.

Table 3. Result of the Push-off Testing of the properties of the Friction (clay soil)

\begin{tabular}{cccc}
\hline $\begin{array}{c}\text { Rate of } \\
\text { movement }\end{array}$ & $\begin{array}{c}\text { Type of } \\
\text { Interfaces }\end{array}$ & $\begin{array}{c}\text { Max. } \\
\text { FRF } \\
(\mathrm{KN})\end{array}$ & $\begin{array}{c}\text { Max. } \\
\mu^{*}\end{array}$ \\
\hline $6 \mathrm{~cm} / \mathrm{hr}$. & Smooth & 1.61 & 0.68 \\
& Rough & 5.23 & 2.22 \\
$9 \mathrm{~cm} / \mathrm{hr}$. & Smooth & 1.9 & 0.81 \\
& Rough & 5.47 & 2.32 \\
$12 \mathrm{~cm} / \mathrm{hr}$. & Smooth & 2 & 0.85 \\
& Rough & 6.01 & 2.55 \\
\hline
\end{tabular}

* Calculated from Eq. (1)

Table 4. Push-off Test Results of the Friction propertie (cement stabilized clay soils)

\begin{tabular}{clll}
\hline $\begin{array}{l}\text { Rate of } \\
\text { movement }\end{array}$ & $\begin{array}{l}\text { Type of } \\
\text { Interfaces }\end{array}$ & $\begin{array}{l}\text { Max. FRF } \\
(\mathrm{KN})\end{array}$ & Max. $\mu^{*}$ \\
\hline $6 \mathrm{~cm} / \mathrm{h}$. & Smooth & 1.94 & 0.82 \\
& Rough & 9.07 & 3.85 \\
$9 \mathrm{~cm} / \mathrm{h}$. & Smooth & 2.05 & 0.87 \\
& Rough & 11.24 & 4.78 \\
$12 \mathrm{~cm} / \mathrm{h}$. & Smooth & 2.21 & 0.94 \\
& Rough & 13.11 & 5.57 \\
\hline
\end{tabular}

\subsection{Screening and Variable Analyses of Base layer Frictions}

Data analyses have been carried out by the screening analysis for the examination of impacts of several parameters on initial value of the FRF, displacements and friction coefficient for selection of significant contributing variables, which has been suggested by [1]. DoE (i.e. 
Design of experiment) software has been deployed in the present study, with results using the chart of Pareto. Charts illustrate the considerable parameters that impact displacement and MCF.

\subsection{Effects of Interface and Cement Stabilization on Friction Coefficient}

After doing the screening, it has been discovered that interface condition represents the higher factor that affects the initial FRF succeeded by cement stabilization, as shown in Fig. 3 which make a higher shearing stiffness because of its

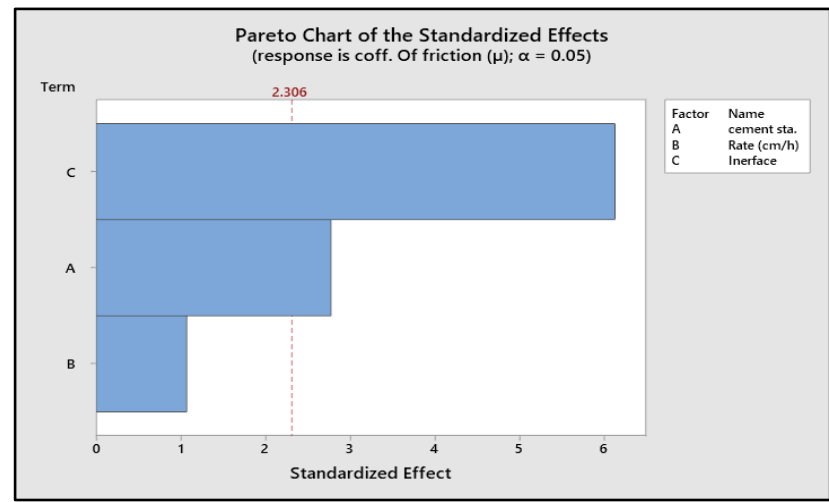

Figure 3. Outcomes of screening analysis for maximum value of. $\mu$

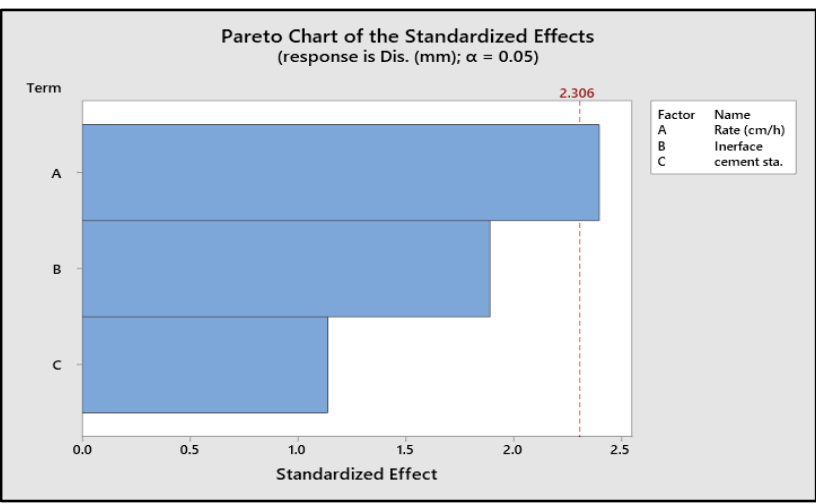

Figure4. Outcomes of the screening analysis for displacement

increased strength. The experimental results have shown that initial FRF is increased through the changes of interface conditions from smooth to the rough and cement stabilization had shown more compliant, as listed in Table 4. In general, the condition of change interface from the smooth to the rough results in an increase in the initial FRF regardless of raise rate of movement, as shown in Fig. 3.

For example, at unsterilized soil base with the changes of interface conditions from the smooth to rough results in increasing initial FRF of $(6,9$ and $12 \mathrm{~cm} / \mathrm{hr}$ ) by (225, 188 and $201 \%)$ respectively, because higher movement leads to high resistance of friction. The findings are matching with previous works [8]. As regards using cement stabilization leads to growth in the initial FRF regardless of change interface condition or rate of movement, as shown in Fig. 5. As illustrated in Fig. 4 the cement stabilization is fewer sensitive factor on the initial FRF, however, increase the movement rate results in raising the initial FRF regardless of change interface condition (i.e., smooth and rough) as shown in Fig. 4.

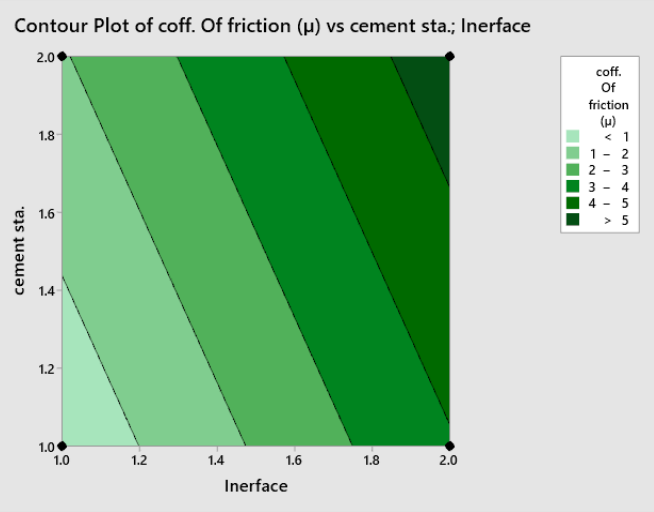

Figure 5. Effect of cement stabilization and interface on coefficient of friction

\section{Conclusions}

1. Initial FRF won't be considerably changed in spite of the rate of the raise movement, where this factor below the impact line of the screening analyses.

2. The change of the conditions of the interface from the smooth to the rough results in an increase in the forces of the friction resistance as a result of the texture of the surface and decreased initial displacements, due to the removal of separator layer will result in the 
creation of more interlock between the surfaces.

3. The maximal friction resistance force value is represented by initial FRF that has been detected in the application of the primary forces.

4. Relating the condition of the interface, in the case where smooth interface movement rates have nearly no impact on the friction coefficient, however, it is increased with rising the rate of the movement in the rough conditions.

5. Subsequent attempts of cycles are always less than the first cycle.

6. When the failure happens at slab-base layer interface, the level of the frictional resistance is directly proportional to the weight of the slab.

7. In the smooth conditions, polythene film is going to be attached to slab bottom, thereby, producing smooth surface for slab to slip above base layer, which results in less frictions.

8. A polythene sheet has the tendency of being a highly sufficient reducer of friction when the sheet of the polythene has been utilized between a slab and base layer; without which, the bonding between the slab and base layer becomes solid and resists more forces.

9. Movement rates should be variable as possible to emulate variations of moisture and temperature throughout the pavement life which may result in the expansion, i.e., the process of the shrinkage can be reversed when there is heavy rain, the pavements begin to absorb rainwater.

\section{Acknowledgements}

The researchers would like to express their thanks to Al-Mustansiriya Univ., Engineering Faculty, Road and Transportation Dept., due to the assistance and guidance they have offered for fulfilling the humble study of the present research. The present paper obtained no funds from any supporting organizations, not-for-profit or private sectors in this study's contents.

\section{Conflicts of interest}

The authors confirm that the publication of this article causes no conflict of interest.

\section{References}

1. Pittman, D. W., and B. F. McCullough. "Development of a RollerCompacted Concrete Pavement Crack and Joint Spacing Model". In Transportation Research Record 1568, TRB, National Research Council, Washington, D.C., 1997, pp. 5264.

2. Lee, S. W. "Horizontal Joint Movements in Rigid Pavements". Ph.D. thesis. Pennsylvania State University, 2000.

3. Al-Fahdawi, J. Z., \& Banyhussan, Q. S. (2020). "Optimization of Eco-friendly Pavement Concrete Mixture Using Response Surface Methodology". Paper presented at the IOP Conference Series: Materials Science and Engineering.https://t.ly/OXNk

4. Diaz, A., Burns, N., \& McCullough, B. (1986). "Behavior of Long Prestressed Pavement Slabs and Design Methodology". Research Report 401-3, Center for Transportation Research, The University of Texas at Austin, November 1986. Retrieved from http://t.ly/n9TM

5. Jeong, J.-H., Park, J.-Y., Lim, J.-S., \& Kim, S.-H. (2014). "Testing and Modelling af Friction Characteristics between Concrete Slab and Subbase Layers". Road Materials and Pavement Design, 15(1),1141-130. https://doi.org/10.1080/14680629.2013.863 161

6. Lee, S. W. (2000). "Characteristics of Friction Between Concrete Slab and Base". KSCE Journal of Civil Engineering, 4(4), 265-275.

7. http://t.ly/NM9Y

8. Maitra, S., Reddy, K., \& Ramachandra, L. (2009). "Experimental Evaluation of Interface Friction And Study of Its Influence on Concrete Pavement Response". Journal of transportation engineering, 135(8), 563571.http://t.ly/AEIw

9. Oladiran, O. G. (2014). "Assessment of Restrained Shrinkage Cracking of Concrete 
Through Elliptical Rings". Brunel University School of Engineering and Design PhD Theses, Retrieved from http://bura.brunel.ac.uk/handle/2438/8224

10. SCRB. (2003). "General Specifications for Roads and Bridges, Ministry of Housing and Construction", Iraq.https://t.ly/G27O

11. Wesevich, J., McCullough, B., \& Burns, N. (1987). "Stabilized Subbase Friction Study for Concrete Pavements". INTERIM REPORT. Retrieved from https://t.ly/CwGE 12. Timms, A. G. (1963). "Evaluating Subgrade Friction-Reducing Mediums for Rigid Pavements". Highway Research Record, 60, 28-38. 